\title{
Education, Income, and Employment and Prevalence of Chronic Disease Among American Indian/Alaska Native Elders
}

\author{
Collette Adamsen, MPA ${ }^{1}$; Shawnda Schroeder, $\mathrm{PhD}^{1}$; Steven LeMire, $\mathrm{PhD}^{2}$; \\ Paula Carter, PhD $^{1}$
}

\section{Accessible Version: www.cdc.gov/pcd/issues/2018/17_0387.htm \\ Suggested citation for this article: Adamsen C, Schroeder S, LeMire S, Carter P. Education, Income, and Employment and Prevalence of Chronic Disease Among American Indian/Alaska Native Elders. Prev Chronic Dis 2018;15:170387. DOI: https:// doi.org/10.5888/pcd15.170387.}

\section{PEER REVIEWED}

\section{Abstract}

\section{Introduction}

Chronic disease studies have omitted analyses of the American Indian/Alaska Native (AI/AN) population, relied on small samples of AI/ANs, or focused on a single disease among AI/ANs. We measured the influence of income, employment status, and education level on the prevalence of chronic disease among 14,632 AI/ AN elders from 2011 through 2014.

\section{Methods}

We conducted a national survey of AI/AN elders ( $\geq 55$ y) to identify health and social needs. Using these data, we computed crosstabulations for each independent variable (annual personal income, employment status, education level), 2 covariates (age, sex), and presence of any chronic disease. We also compared differences in values and used a binary logistic regression model to control for age and sex.

\section{Results}

Most AI/AN elders (89.7\%) had been diagnosed with at least one chronic disease. AI/AN elders were also more than twice as likely to have diabetes and more likely to have arthritis. AI/AN elders with middle-to-low income levels and who were unemployed were more likely to have a chronic disease than were high-income and employed AI/AN elders.

\section{Conclusion}

Addressing disparities in chronic disease prevalence requires focus on more than access to and cost of health care. Economic development and job creation for all age cohorts in tribal communities may decrease the prevalence of long-term chronic diseases and may improve the financial status of the tribe. An opportunity exists to address health disparities through social and economic equity among tribal populations.

\section{Introduction}

Chronic diseases are the leading causes of death and disability in the United States, and nearly half of adults are diagnosed with one or more chronic conditions (1). Many of these conditions are disproportionally prevalent among American Indian/Alaska Natives (AI/ANs) $(2,3)$. The prevalence of chronic conditions among AI/ ANs results in low life expectancy $(4,5)$, and AI/ANs are more likely than all other races in the United States to die of heart disease, diabetes, chronic lower respiratory disease, cirrhosis, stroke, pneumonia, kidney disease, and hypertension $(4,6)$.

$\mathrm{AI} / \mathrm{ANs}$ are more likely than their peers to be at risk for chronic disease as a result of income, education level, employment status, and health behaviors $(7,8)$. One in $4 \mathrm{AI} / \mathrm{ANs}$ live in poverty, and tribal communities report the lowest employment rate nationally. The median annual personal income for $\mathrm{AI} / \mathrm{ANs}$ is far below the national average (7,8). During 2001 and 2002, AI/AN elders (aged $\geq 55 \mathrm{y})$ were at greater risk for chronic disease than their non-Hispanic white peers when social status and health behaviors were examined (9). However, the study with these findings relied on a small sample $(3,5)$, was conducted before the Patient Protection and Affordable Care Act and the US recession, and did not explore subgroups in the AI/AN elder population. Other national surveys on the prevalence and risk factors of chronic disease had a 
small sample of AI/ANs, were disease-specific, omitted analyses of the AI/AN population, or had cell sizes that were too small to report (9-11).

The objective of this national analysis was to identify which social factors, if any, influence the prevalence of chronic diseases among AI/AN elders (aged $\geq 55 \mathrm{y}$ ). We assessed the association of self-reported income, employment status, and education level on the prevalence of chronic disease among 14,632 AI/AN elders from 2011 through 2014.

\section{Methods}

The US Department of Health and Human Services' Administration for Community Living funds the National Resource Center on Native American Aging (NRCNAA). Data used in this study were taken from the NRCNAA's 2011-2014 Survey of Elders, which has been administered every 3 years since 2001 .

\section{Survey}

NRCNAA faculty developed the paper survey to assist tribes, villages, and homesteads nationally in creating a record of the health and social needs of their elders. The results satisfy the requirement for Title VI Nutrition and Caregiving Grant under the Administration for Community Living. Self-reported data are collected every 3 years on general health status; activities of daily living; vision, hearing, and dental care screenings; health care access; tobacco and alcohol use; weight and nutrition; social support and housing; demographic characteristics; and social functioning. Survey measures mirror those of nationally administered questionnaires to allow for comparison to the US population (12). Data for this study were taken from Cycle V, which covers self-reported health status for AI/AN elders from 2011 through 2014. The University of North Dakota's institutional review board approved the survey and the proposed method of research; the Official Tribal Council for each participating tribe provided approval through a tribal resolution for the study.

The survey is administered via a Scantron form (Scantron Corporation) on which respondents fill in circles that correspond to the most appropriate responses. The survey also has several write-in responses that are input through image reader technology. Surveys are scanned in-house by NRCNAA staff. To build tribal capacity and improve trust among participants, trained members of the tribe administered the paper surveys to participating elders, reading the questions and filling in the corresponding answers on the form. These individuals were not paid by the NRCNAA directly, but many were employees of the Title VI program. The par- ticipating elders were allowed to skip questions they were not comfortable answering. Participating tribes returned all completed surveys to the NRCNAA research team.

All survey data are owned by the tribes. The NRCNAA houses the data, but staff report only in aggregate and under tribal approval. Tribal-specific reports are shared with Title VI directors, who then provide the data to members of the community and to community health groups (to include local public health units). NRCNAA staff and faculty (including authors) include both non-Natives and enrolled members of federally recognized tribes.

\section{Study population}

Tribes participating in the Title VI Nutrition and Caregiving Grant were recruited through the Title VI tribal directors, although we invited all tribes to participate. The 2011-2014 survey cycle included tribally affiliated elders aged 55 years or older. Participants represented all US regions, and 262 (of 566) federally recognized tribes. Within each tribe, researchers identified a simple random sample based on the total number of elders enrolled. The prestudy calculation of required sample size was determined by applying a formula to each tribe. The formula was applied to each of the 262 tribes independently to ensure that the sample obtained was representative of that tribe and not an aggregate representation of all participating tribes collectively. This method allowed results that were representative and generalizable to their population to be shared with each tribe and not to all participating tribes.

Individuals were included in the study if they were aged 55 years or older, an enrolled member of a federally recognized tribe, and eligible to accept services under the Title VI Nutrition and Caregiving Grants. The survey had a $68.5 \%$ response rate $(14,632$ of 21,361 respondents).

\section{Measures}

Independent variables were employment status (employed, unemployed/retired); education level (no education or less than a high school diploma, high school graduate, any education beyond high school); and annual personal income $(<\$ 15,000$ [low]; $\$ 15,000-\$ 49,999$ [middle]; $\geq \$ 50,000$ [high]). Income level was listed categorically in the survey instrument. We controlled for age (55-64 y, 65-74 y, $\geq 75$ y) and sex (male/female). The dependent variable was diagnosis of any chronic disease. Participants replied to the question, "Has a doctor ever told you that you had any of the following diseases (please mark all that apply)?" The presence of chronic disease was assessed with 10 conditions: arthritis, congestive heart failure, stroke, asthma, cataracts, high blood pressure, osteoporosis, depression, diabetes, and cancer. We included

\footnotetext{
The opinions expressed by authors contributing to this journal do not necessarily reflect the opinions of the U.S. Department of Health and Human Services, the Public Health Service, the Centers for Disease Control and Prevention, or the authors' affiliated institutions.
} 
cataracts in our analysis because literature on the elderly population more commonly refer to this vision impairment as a chronic condition, and the World Health Organization indicates it as a priority eye disease $(13,14)$. Furthermore, diabetes is associated with the development of cataracts.

\section{Statistical analysis}

We used SPSS (IBM Corporation) to compute summary statistics to identify characteristics of the study population. To determine the prevalence of chronic disease, we created a binary variable to include respondents with at least one of the 10 identified chronic conditions and those without. We converted age from a ratio to a categorical variable, a method most commonly used in health research (15), and converted education level from a 0 to 17 scale to a 3 -point scale. We determined the percentage of participants with and without chronic conditions within each category of the independent variables. We computed cross-tabulations for each independent variable and presence of any chronic disease and used a binary logistic regression model $(P \leq .05)$. In the regression model, researchers controlled for age (categorically), and sex (male/female).

\section{Results}

Respondents were mostly female (62.3\%), unemployed/retired $(69.4 \%)$, aged 55 to 64 years $(40 \%)$, and middle income $(56.1 \%)$ and had completed some education beyond high school (38.7\%). Most AI/AN elders (89.7\%) had been diagnosed with at least one of 10 chronic diseases; $69.8 \%$ had 2 or more chronic conditions, and $45.2 \%$ had 3 or more. The most common chronic diseases among AI/AN elders were high blood pressure (58.9\%), diabetes $(53.9 \%)$, and arthritis (47.2\%) (Table 1$)$.

The prevalence of having one or more chronic diseases was significantly higher among female (91.1\%) than male $(87.5 \%)$ elders; among elders aged 65 to 74 years and aged 75 years or older than those aged 55 to 64 years; among low-income and middle-income elders than high-income elders; among unemployed $(92.4 \%)$ than employed (83.9\%) elders; and among elders who had not completed high school than those with a high school diploma and those with education beyond high school (all $P \leq .05$ ) (Table 2 ).

When we controlled for age and sex, middle-income AI/AN elders were 1.3 times as likely as high-income AI/AN elders to be diagnosed with one or more chronic diseases (Table 3). Employed $\mathrm{AI} / \mathrm{AN}$ elders were less likely than unemployed AI/AN elders to be diagnosed with one or more chronic diseases. When we controlled for age and sex, educational attainment did not have a significant influence on the likelihood that an AI/AN elder would be diagnosed with at least one chronic disease (Table 3).

\section{Discussion}

AI/AN elders have a higher prevalence of chronic disease than other races in the US population yet are largely overlooked in research and in proposed federal, social, and tribal interventions. We identified the influence of social variables on the health status of $\mathrm{AI} / \mathrm{AN}$ elders and found that $89.7 \%$ of elders surveyed from 2011 through 2014 had at least one chronic disease. Comparatively, the National Council on Aging, using 2015 Medicaid and Medicare data, reported that $80 \%$ of older adults of all races had at least one chronic condition $(16,17)$.

High blood pressure, diabetes, and arthritis were the 3 leading chronic conditions for AI/AN elders. The frequency of hypertension among AI/AN elders (58.9\%) nearly mirrored the national average $(58 \%)(16,17)$. However, other chronic conditions among $\mathrm{AI} / \mathrm{AN}$ elders occurred at double the national average. Specifically, $54 \%$ of the AI/AN elders reported diabetes, compared with only $27 \%$ of the US population aged 65 years or older. Roughly $31 \%$ of all US adults aged 65 or older were diagnosed with arthritis in 2015 , compared with $47.2 \%$ of $\mathrm{AI} / \mathrm{AN}$ elders $(16,17)$.

Federal, state, community, and tribal interventions and policies must explore the prevalence of chronic conditions by race, rather than solely examine general prevalence of chronic disease. Data for $\mathrm{AI} / \mathrm{AN}$ elders and for the general US elder population identify the prevalence of similar chronic diseases, but special attention must be paid to AI/AN elders. The significant disparity among diseases (eg, diabetes) may also indicate that programs designed to reduce the prevalence of that disease among the general US elder population are not effective, are not reaching tribal populations, or both. As public health units become increasingly responsible for the prevention of chronic disease, these data may be used to develop interventions that are population-specific for each chronic condition.

We established the prevalence of chronic disease among AI/AN elders and then identified demographic categories with higher prevalence of chronic disease. As in national trends, female AI/AN elders were significantly more likely than male AI/AN elders to have a chronic condition (18-21). Approximately $91 \%$ of AI/AN female elders had at least one chronic disease, compared with $87.5 \%$ of $\mathrm{AI} / \mathrm{AN}$ male elders. As age increased among elders, so did the likelihood of having a chronic condition, which mirrors national trends (21).

The opinions expressed by authors contributing to this journal do not necessarily reflect the opinions of the U.S. Department of Health and Human Services, the Public Health Service, the Centers for Disease Control and Prevention, or the authors' affiliated institutions. 
The prevalence of chronic disease among AI/ANs who were employed was significantly lower than for those who were unemployed; similarly, those with high income were less likely than middle-income and low-income elders to have a chronic condition. These trends were also reported by the National Center for Health Statistics for the general US population in 2013 (15). Cost of care is the most common reason patients with chronic conditions delay treatment or prevention (regardless of income or employment status) (22). Therefore, there is heightened concern for the AI/AN elder population, as most were unemployed and middle-income to low-income and less likely to then afford health care services both on and off of the reservation.

Although the Indian Health Service (IHS) provides care at reduced cost to AI/ANs on the reservation, access to that care is limited because IHS consistently is underfunded $(23,24)$. During 2009 and 2010, Indian health expenditures per capita were one-third of the expenditures for Medicare, and they were lower per capita than those for veterans, Medicaid patients, and participants in the Federal Employees Health Benefits Program (25). AI/ANs also have high uninsured rates, making it more difficult to access care outside of IHS, especially for those who are low-income (23). These issues of access to affordable care likely contribute to the increased prevalence of chronic disease among AI/AN elders who are low-income and unemployed.

To prevent chronic diseases and improve the health status of those with chronic diseases, communities and programs can investigate job creation for $\mathrm{AI} / \mathrm{AN}$ elders. Elders may also require resources like transportation and job training. Economic development and job creation for all age cohorts in tribal communities will benefit long-term chronic disease prevalence and can improve the financial status of the tribe.

Results also indicate a need to identify solutions that are focused more on population health than on access to or cost of care. Communities have developed programs that rely on collaboration between public health units, at-risk tribal populations, and local health care systems to address prevention and early detection services (26-29). As public health units take on a larger responsibility for population health, this data can and is being used to target population subgroups in the AI/AN population who have an increased prevalence of chronic conditions. Tribal public health units can identify subgroups (eg, women) that have a higher prevalence of certain chronic conditions and provide education and prevention that is specific to them (26). Likewise, as AI/ANs seek information, prevention, and treatment outside of IHS, local public health units need to recognize that $\mathrm{AI} / \mathrm{AN}$ elders that use their services likely have multiple chronic conditions. Shaw et al discussed health literacy and the need for communities and public health units to understand the socioeconomic and cultural differ- ences of at-risk populations (29). Programs exist that effectively incorporate cultural traditions in public and tribal health services $(10,27,29,30)$. These models can improve the health of tribal communities and their elders.

This study has several limitations. First, the national definition of elderly is typically aged 65 or older. We assessed chronic disease among AI/AN elders aged 55 or older. This decision was in response to the lower average life expectancy of AI/ANs compared with that of the general US population. However, doing so made it difficult to compare AI/AN elders' prevalence of chronic disease to the prevalence of disease among all older people in the United States with any certainty. This limitation, however, provides a conservative measure of chronic disease among AI/ANs elders, recognizing that research indicates a higher prevalence among older cohorts. Omitting respondents aged 55 to 64 years would have resulted in higher prevalence rates for the AI/AN population.

The self-reported diagnosis of a chronic disease may also be problematic. There is risk of both underreporting and overreporting. Elders may not want to identify with a given disease or may have low health literacy and misunderstand or forget a diagnosis. Elders may also self-diagnose and indicate a chronic disease that has not been clinically diagnosed. Finally, the results addressed AI/ ANs as one collective people, although AI and AN populations experience vastly different health barriers, practice different traditions, and vary in some health outcomes. The decision to speak to the AI/AN elder population collectively was made to ensure a large enough sample to generalize for tribal populations and to have large enough cell sizes to conduct both a factor analysis and cross-tabulations. Future research may investigate the 2 populations independently to determine whether differences in the prevalence of chronic disease exist. In addition, the variable "employment" previously omitted a distinction between "retired" and "unemployed," limiting respondents to indicate only "yes, employed full-time"; "yes, employed part-time"; or not employed. Future cycles of the survey will now include "retired" and "unemployed" as separate categories, which will allow for more granularity in the discussion of chronic disease among people who are not employed.

We found a higher overall prevalence of chronic disease among AI/AN elders compared with the older US population and substantially higher rates of both diabetes and arthritis among AI/AN elders. Finally, we found that a significantly higher prevalence of chronic disease exists among AI/AN elders who are unemployed and middle-income or low-income. These findings call for economic and social interventions outside those typically related to access to care. These results may be used to develop public health and community programs and interventions at the tribal level dedicated to improving the health of AI/AN elders, especially those

\footnotetext{
The opinions expressed by authors contributing to this journal do not necessarily reflect the opinions of the U.S. Department of Health and Human Services, the Public Health Service, the Centers for Disease Control and Prevention, or the authors' affiliated institutions.
} 
with hypertension, arthritis, or diabetes, and those who are middleto low-income or unemployed. An opportunity exists to address health disparities through social and economic equity among tribal populations.

\section{Acknowledgments}

Support for this research was provided by the Administration of Community Living under grant no. 900I0008-03-00. The information, conclusions, and opinions expressed in this article are those of the authors, and no endorsement by the Administration of Community Living, the University of North Dakota, or the NRCNAA is intended or should be inferred.

\section{Author Information}

Corresponding Author: Shawnda Schroeder, PhD, The University of North Dakota, Center for Rural Health, School of Medicine \& Health Sciences, 1301 N. Columbia Rd, Stop 9037, Grand Forks, ND 58202. Telephone: 701-777-0787. Email: Shawnda.schroeder@med.und.edu.

Author Affiliations: ${ }^{1}$ The University of North Dakota, Center for Rural Health, School of Medicine \& Health Sciences, Grand Forks, North Dakota. ${ }^{2}$ The University of North Dakota, College of Education \& Human Development, Grand Forks, North Dakota.

\section{References}

1. Centers for Disease Control and Prevention. Chronic disease overview; 2012. https://www.cdc.gov/chronicdisease/ overview/. Accessed June 1, 2017.

2. Leavitt MO, McSwain RG, Church RM, Paisano EL. Indian Health Service regional differences in Indian health, 2002-2003 edition. Bethesda (MD): US Department of Health and Human Services, Indian Health Service; 2008.

3. James C, Schwartz K, Berndt J.A profile of American Indians and Alaska Natives and their health coverage [issue brief]. Race, ethnicity, and health care. The Henry J. Kaiser Family Foundation; 2009. p. 1-13.

4. US Department of Health and Human Services, Indian Health Service. Indian health disparities; 2015. https:/www.ihs.gov/ newsroom/index.cfm/factsheets/disparities/. Accessed May 15, 2017.

5. Espey DK, Jim MA, Cobb N, Bartholomew M, Becker T, Haverkamp D, et al. Leading causes of death and all-cause mortality in American Indians and Alaska Natives. Am J Public Health 2014;104(Suppl 3):S303-11.
6. Perry S, Foster J. Health reform: help for American Indians and Alaska Natives. Families USA Minority Health Initiatives; 2010. http://familiesusa.org/sites/default/files/product documents/Help-for-American-Indians.pdf. Accessed April 15, 2017.

7. US Census Bureau. American Community Survey, 2011-2015 data tables. https://www.census.gov/newsroom/press-releases/ 2017/acs-selected-population-tables-aian.html. Accessed July 14, 2017.

8. Pettit KLS, Kingsley GT, Biess J, Bertumen K, Pindus N, Narducci C, Budde A. Continuity and change: demographic, socioeconomic, and housing conditions of American Indians and Alaska Natives. US Department of Housing and Urban Development; 2014. p. 1-85.

9. Denny CH, Holtzman D, Goins RT, Croft JB. Disparities in chronic disease risk factors and health status between American Indian/Alaska Native and White elders: findings from a telephone survey, 2001 and 2002. Am J Public Health 2005;95(5):825-7.

10. Galloway JM. Cardiovascular health among American Indians and Alaska Natives: successes, challenges, and potentials. Am J Prev Med 2005;29(5,Suppl 1):11-7.

11. Redwood DG, Lanier AP, Johnston JM, Asay ED, Slattery ML. Chronic disease risk factors among Alaska Native and American Indian people, Alaska, 2004-2006. Prev Chronic Dis 2010;7(4):A85.

12. Native American Resource Center on Native American Aging. Needs assessment, identifying our needs: a survey of elders. https://www.nrcnaa.org/needs-assessment. Accessed July 14, 2017.

13. Chi MJ, Lee CY, Wu SC. The prevalence of chronic conditions and medical expenditures of the elderly by chronic condition indicator (CCI). Arch Gerontol Geriatr 2011;52(3):284-9.

14. Prevention of blindness and visual impairment: priority eye diseases. World Health Organization; 2017. http:// www.who.int/blindness/causes/priority/en/index 1.html. Accessed August 23, 2017.

15. US Department of Health and Human Services, National Center for Health Statistics. National Health Interview Survey data tables, 2013. https://www.cdc.gov/nchs/nhis/index.htm. Accessed July 6, 2017.

16. National Council on Aging. Top 10 chronic conditions in adults $65+$ and what you can do to prevent or manage them. https://www.ncoa.org/wp-content/uploads/10-CommonChronic-Conditions-Older-Adults-ncoa.png. Accessed June 28, 2017.

The opinions expressed by authors contributing to this journal do not necessarily reflect the opinions of the U.S. Department of Health and Human Services, the Public Health Service, the Centers for Disease Control and Prevention, or the authors' affiliated institutions. 
17. Centers for Medicare \& Medicaid Services. 2015 Chronic conditions prevalence state/county data tables; 2015. https:// www.cms.gov/Research-Statistics-Data-and-Systems/ Statistics-Trends-and-Reports/Chronic-Conditions/CC Main.html. Accessed July 10, 2017.

18. Ward BW, Schiller JS. Prevalence of multiple chronic conditions among US adults: estimates from the National Health Interview Survey, 2010. Prev Chronic Dis 2013; 10:120203.

19. Kuri-Morales P, Emberson J, Alegre-Díaz J, Tapia-Conyer R, Collins R, Peto R, et al. The prevalence of chronic diseases and major disease risk factors at different ages among 150,000 men and women living in Mexico City: cross-sectional analyses of a prospective study. BMC Public Health 2009;9(9):9.

20. Gerteis J, Izrael D, Deitz D, et al.Multiple chronic conditions chartbook. Publication no. Q14-0038. Rockville (MD): Agency for Healthcare Research and Quality; April 2014.

21. Freid VM, Bernstein AB, Bush MA. Multiple chronic conditions among adults aged 45 and over: trends over the past 10 years. NCHS data brief, no. 100. Hyattsville (MD): National Center for Health Statistics; 2012.

22. Ward BW. Barriers to health care for adults with multiple chronic conditions: United States, 2012-2015. NCHS data brief, no. 275. Hyattsville (MD): National Center for Health Statistics; 2017. https://www.cdc.gov/nchs/products/databriefs/ db275.htm. Accessed March 27, 2017.

23. Warne D, Frizzell LB. American Indian health policy: historical trends and contemporary issues. Am J Public Health 2014;104(Suppl 3):S263-7.

24. US Commission of Civil Rights. A quiet crisis: federal funding and unmet need in Indian country. Washington (DC): US Commission on Civil Rights; 2003. p. 35-49.

25. National Tribal Budget Formulation Workgroup. National tribal recommendation for the Indian Health Service: fiscal year 2013 budget. Washington (DC): US Department of Health and Human Services; 2011.

26. Bauer UE, Briss PA, Goodman RA, Bowman BA. Prevention of chronic disease in the 21 st century: elimination of the leading preventable causes of premature death and disability in the USA. Lancet 2014;384(9937):45-52.

27. Gittelsohn J, Rowan M. Preventing diabetes and obesity in American Indian communities: the potential of environmental interventions. Am J Clin Nutr 2011;93(5):1179S-83S.

28. Bodenheimer T, Chen E, Bennett HD. Confronting the growing burden of chronic disease: can the U.S. health care workforce do the job? Health Aff (Millwood) 2009; 28(1):64-74.

29. Shaw SJ, Huebner C, Armin J, Orzech K, Vivian J. The role of culture in health literacy and chronic disease screening and management. J Immigr Minor Health 2009;11(6):460-7.
30. Jernigan VB. Community-based participatory research with Native American communities: the chronic disease selfmanagement program. Health Promot Pract 2010; 11(6):888-99.

\footnotetext{
The opinions expressed by authors contributing to this journal do not necessarily reflect the opinions of the U.S. Department of Health and Human Services, the Public Health Service, the Centers for Disease Control and Prevention, or the authors' affiliated institutions.
}

6 Centers for Disease Control and Prevention - www.cdc.gov/pcd/issues/2018/17_0387.htm 


\section{Tables}

Table 1. Percentage of American Indian/Alaska Native (Al/AN) Elders With Diagnosed Chronic Disease (N=14,632), by Demographic Category, Survey of Elders, 2011-2014

\begin{tabular}{|c|c|c|c|c|c|c|c|c|c|c|}
\hline Demographic Characteristic & HBP & Diabetes & Arthritis & Cataracts & Depression & Asthma & Osteoporosis & Cancer & CHF & Stroke \\
\hline Overall & 58.9 & 53.9 & 47.2 & 22.5 & 15.0 & 13.7 & 10.8 & 9.0 & 8.9 & 7.7 \\
\hline \multicolumn{11}{|l|}{$\operatorname{Sex}^{a}$} \\
\hline Male & 59.6 & 52.9 & 40.0 & 19.1 & 11.4 & 9.4 & 3.9 & 10.0 & 10.1 & 8.3 \\
\hline Female & 58.6 & 54.6 & 51.5 & 24.5 & 17.1 & 16.3 & 14.9 & 8.3 & 8.2 & 7.3 \\
\hline \multicolumn{11}{|l|}{ Age, $y^{a}$} \\
\hline $55-64$ & 54.5 & 49.7 & 43.0 & 12.5 & 17.4 & 14.8 & 8.7 & 6.4 & 5.7 & 5.5 \\
\hline $65-74$ & 61.3 & 57.3 & 48.4 & 24.3 & 13.9 & 13.7 & 10.9 & 9.4 & 9 & 8.2 \\
\hline$\geq 75$ & 62.8 & 55.9 & 52.5 & 36.4 & 12.5 & 11.6 & 13.9 & 12.6 & 14.2 & 10.7 \\
\hline \multicolumn{11}{|l|}{ Annual personal income, $\$^{a}$} \\
\hline$<15,000$ (Low) & 58.3 & 57.5 & 49.6 & 21.7 & 16.2 & 14.6 & 11.2 & 7.8 & 8.7 & 8.6 \\
\hline 15,000-49,999 (Middle) & 59.8 & 53.3 & 46.6 & 23.0 & 14.4 & 13.5 & 10.7 & 9.5 & 9.3 & 7.5 \\
\hline$\geq 50,000$ (High) & 55.3 & 44.8 & 37.5 & 18.6 & 11.4 & 11.1 & 9.5 & 10.7 & 6.1 & 3.6 \\
\hline \multicolumn{11}{|l|}{ Employment status $^{\mathrm{a}}$} \\
\hline Unemployed or retired & 61.9 & 57.3 & 51.7 & 26.6 & 17.0 & 14.5 & 12.5 & 10.2 & 10.9 & 9.5 \\
\hline Employed & 53.1 & 47.1 & 36.6 & 13.3 & 10.4 & 12.0 & 6.6 & 6.4 & 4.5 & 3.5 \\
\hline \multicolumn{11}{|l|}{ Education level $^{a}$} \\
\hline $\begin{array}{l}\text { Less than a high school } \\
\text { diploma }\end{array}$ & 62.2 & 57.1 & 52.2 & 27.5 & 15.4 & 14.1 & 10.9 & 8.7 & 11.1 & 9.5 \\
\hline High school graduate & 58.8 & 52.7 & 45.8 & 20.5 & 13.3 & 11.7 & 9.7 & 8.2 & 8.3 & 7.4 \\
\hline Education beyond high school & 56.6 & 52.7 & 44.8 & 20.7 & 16.2 & 15.0 & 11.6 & 9.8 & 8.0 & 6.7 \\
\hline
\end{tabular}

Abbreviations: $\mathrm{CHF}$, congestive heart failure; HBP, high blood pressure.

a Significant at $P \leq .05$. 
Table 2. Demographic Characteristics of American Indian/Alaska Native Elders With and Without a Diagnosed Chronic Disease $(\mathrm{N}=14,632)$, Survey of Elders, 2011-2014

\begin{tabular}{|c|c|c|}
\hline \multirow[b]{2}{*}{ Demographic Characteristic } & With Chronic Disease $\left(n=13,123^{a}\right)$ & No Chronic Disease $\left(n=1,509^{a}\right)$ \\
\hline & \multicolumn{2}{|c|}{ \% (No.) } \\
\hline \multicolumn{3}{|l|}{ Sex } \\
\hline Male & $87.5(4,768)$ & $12.5(681)$ \\
\hline Female & $91.1(8,212)$ & $8.9(807)$ \\
\hline \multicolumn{3}{|l|}{ Age, y } \\
\hline $55-64$ & $85.5(5,003)$ & $14.5(848)$ \\
\hline $65-74$ & $91.6(4,849)$ & $8.4(445)$ \\
\hline$\geq 75$ & $93.8(3,271)$ & $6.2(216)$ \\
\hline \multicolumn{3}{|l|}{ Annual personal income, $\$$} \\
\hline$<15,000$ (Low) & $90.6(4,392)$ & $9.4(455)$ \\
\hline 15,000-49,999 (Middle) & $90.0(6,655)$ & $10.0(737)$ \\
\hline$\geq 50,000$ (High) & $84.6(794)$ & $15.4(144)$ \\
\hline \multicolumn{3}{|l|}{ Employment status } \\
\hline Employed & $83.9(3,459)$ & $16.1(666)$ \\
\hline Unemployed or retired & $92.4(8,623)$ & $7.6(712)$ \\
\hline \multicolumn{3}{|l|}{ Education level } \\
\hline Less than a high school diploma & $92.2(3,787)$ & $7.8(319)$ \\
\hline High school graduate & $88.8(4,192)$ & $11.2(529)$ \\
\hline Education beyond high school & $88.7(4,942)$ & $11.3(630)$ \\
\hline
\end{tabular}

${ }^{\text {a }}$ Subcategorical totals may not sum to values for $n$ because of missing data. Percentages for each subcategory omit missing data. 
Table 3. Binary Logistic Regression Models for Presence of Chronic Disease Among American Indian/Alaska Native Elders ( $N=14,632)$, by Income, Employment Status, and Education Levels, Controlling for Age and Sex, Survey of Elders, 2011-2014

\begin{tabular}{|c|c|c|c|c|}
\hline Variable & B (Standard Error) & Wald $x^{2}$ & $P$ Value ${ }^{a}$ & $\operatorname{Exp}(B)$ \\
\hline \multicolumn{5}{|l|}{ Income, $\$$} \\
\hline$\geq 50,000{\text { (High })^{b}}^{b}$ & - & 11.90 & .003 & - \\
\hline 15,000-49,999 (Middle) & $0.261(0.105)$ & 6.18 & .01 & 1.298 \\
\hline$<15,000$ (Low) & $0.060(0.117)$ & 0.27 & .60 & 1.062 \\
\hline \multicolumn{5}{|l|}{ Education } \\
\hline Education beyond high school $^{b}$ & - & 7.18 & .03 & - \\
\hline High school graduate & $-0.088(0.072)$ & 1.49 & .22 & 0.916 \\
\hline Less than a high school diploma & $0.143(0.087)$ & 2.72 & .10 & 1.154 \\
\hline Employed & $-0.715(0.071)$ & 100.29 & $<.001$ & 0.489 \\
\hline \multicolumn{5}{|l|}{ Age, y } \\
\hline$\geq 75^{\mathrm{b}}$ & - & 49.69 & $<.001$ & - \\
\hline $65-74$ & $-0.157(0.101)$ & 2.44 & .12 & 0.854 \\
\hline $55-64$ & $-0.568(0.098)$ & 33.57 & $<.001$ & 0.566 \\
\hline Female sex & $0.449(0.062)$ & 51.87 & $<.001$ & 1.566 \\
\hline
\end{tabular}

${ }^{\text {a }} P$ values calculated using Wald $x^{2}$ test.

${ }^{\mathrm{b}}$ Reference group; cells with a dash indicate that the value was not calculated. 